\title{
Synthesis, Structure and Hirshfeld Surface Analysis of Phosphine-Imidazolium Salt
}

\author{
Alexey V. Smarun ${ }^{1}$, Violeta Jevtovic ${ }^{2}$ and Rakesh Ganguly ${ }^{3, *(D)}$ \\ 1 CBC, SPMS, NTU, Singapore 637371, Singapore; alexsmarun@gmail.com \\ 2 Department of Chemistry College of Science, University of Hail, P.O. Box 2440 Hail, Saudi Arabia; \\ v.jevtovic@uoh.edu.sa \\ 3 Department of Chemistry, Shiv Nadar University, Gautam Buddha Nagar 201314, India \\ * Correspondence: rakesh.ganguly@snu.edu.in
}

Received: 14 May 2020; Accepted: 22 May 2020; Published: 8 June 2020

\begin{abstract}
In the field of homogeneous catalysis, particularly in anti-Markovnikov hydration, sterically demanding phosphine ligand has found to be very effective. Here we report the crystal structure of a phosphine-imidazolium salt which crystallized in monoclinic space group $P_{21 / c}$ with a $=16.6623(13)$ $(\AA), \mathrm{b}=10.6686(8)(\AA)$ and $\mathrm{c}=12.8916(11)$ with $\beta=110.232(2)$. Hirshfeld surface analysis show that the halogen-hydrogen interaction leads to a formation of 1D chain.
\end{abstract}

Keywords: crystal structure; halogen-hydrogen interaction; Hirshfeld surface analysis

\section{Introduction}

Sterically demanding phosphine ligands have found their application in homogeneous catalysis. A particular group of phosphine ligands bearing imidazolyl moieties provides transition metal complexes based on them with a unique set of reactivities. In 2001, a ruthenium complex with two phosphines $\mathrm{Ph}_{2} \mathrm{PIm}$ (where Im = 4-tert-butyl-1-methylimidazol-2-yl) was reported to catalyze the anti-Markovnikov hydration of terminal alkynes [1], while a ruthenium complex with chelating ligand ${ }^{i} \mathrm{Pr}_{2} \mathrm{PIm}$ exhibited remarkable activity in reactions of alkene isomerization and deuteration $[2,3]$. The latter's more sterically demanding analog, ${ }^{t} \mathrm{Bu}_{2} \mathrm{PIm}$, was used in a study of $\operatorname{Pd}(0)$ and $\operatorname{Pd}(\mathrm{II})$ complexes, where its significant steric bulkiness was shown to enforce chelation [4]. The same ligand was also recently utilized in a systematic study of terminal alkenes isomerization catalyzed by Ru-based complexes containing cyclopentadienyl rings with different degrees of methylation [5], as well as in a work on site-selective deuteration of polyalkenes [6]. Here we report the synthesis and X-ray crystal structure of this ligand's protonated form—the phosphine-imidazolium salt [ $\left.{ }^{\mathrm{t}} \mathrm{Bu}_{2} \mathrm{PImH}\right] \mathrm{PF}_{6}$ (1).

\section{Results}

Protonation of bis-(tert-butyl) (4- tert-butyl-1-methylimidazol-2-yl) phosphine in the presence of $\mathrm{HCl}$ followed by the anion replacement with $\mathrm{KPF}_{6}$ leads to theaa formation of rather air and moisture stable protonated phosphine- imidazolium salt $\left[{ }^{t} \mathrm{Bu}_{2} \mathrm{PImH}\right] \mathrm{PF}_{6}$. Slow evaporation of an acetone solution of $\left[{ }^{\mathrm{t}} \mathrm{Bu}_{2} \mathrm{PImH}\right] \mathrm{PF}_{6}$ leads to the formation of colorless block of single crystals. The resulting molecular structure is shown in Figure 1 and selected bond lengths and angles are given in Table 1 (details in supplementary, CCDC 2003050). A search of the Cambridge Structural Database (Version 2.0.5, last update March 2020) does not reveal any similar phosphine structures. Crystal parameters of closely related protonated Imidazole ligands [7] are similar to the reported crystal structure in this study. 


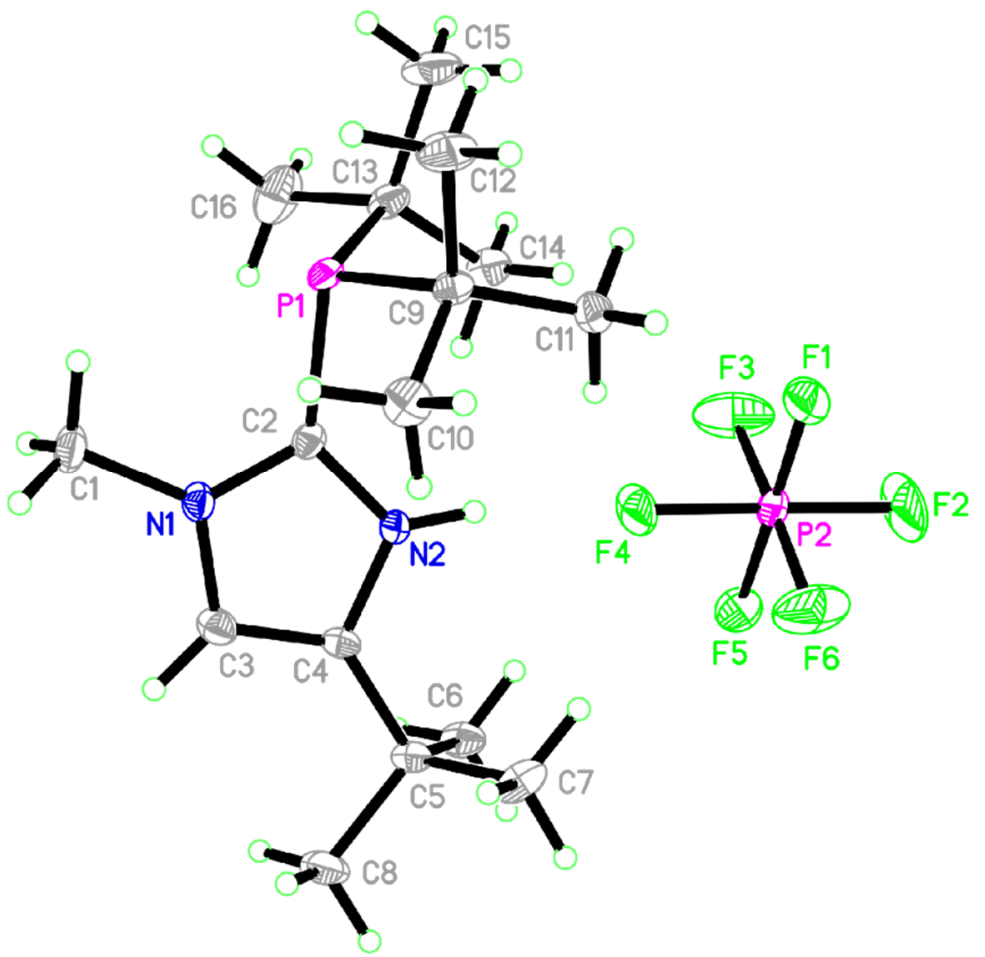

Figure 1. ORTEP diagram of complex 1 with thermal ellipsoids drawn at the $50 \%$ probability level.

Table 1. Selected bond parameters of complex 1.

\begin{tabular}{cccc}
\hline \multicolumn{2}{c}{ Bond Lengths (̊̊) } & \multicolumn{2}{c}{ Bond Angles (deg) } \\
\hline P1-C2 & $1.8395(2)$ & C2 -P1 -C9 & $105.05(1)$ \\
\hline P1-C9 & $1.8858(2)$ & C2 -P1 -C13 & $130.96(1)$ \\
\hline P1-C13 & $1.8807(2)$ & C9 -P1 -C13 & $123.96(1)$ \\
\hline P2-F2 & $1.5829(1)$ & F2 -P2 -F5 & $117.97(1)$ \\
\hline P2-F4 & $1.6102(1)$ & F3 -P2 -F4 & $107.63(1)$ \\
\hline
\end{tabular}

Hirschfeld Surface Analysis

A Hirshfeld surface analysis was performed using Crystal Explorer [8]. The Hirshfeld surface mapped using an iso value of 0.5 , with red contours indicating a contact less than the sum of the Van Der Waals radii of the respective elements, while blue and while contours indicate that the nearest external atom is at a distance greater than or equal to the sum of the Van Der Waals radii, respectively from the atomic coordinate as shown in Figure 2.

The Hirshfeld analysis of $\mathbf{1}$ reveals an array of halogen-hydrogen interactions [9] involving the $\mathrm{F}$ atoms, ranging from liner Type 1 [10] short $\mathrm{N}-\mathrm{H} \cdots \mathrm{F}$ contact between $\mathrm{H} 2$ and the $\mathrm{F} 4$ from the $\mathrm{PF}_{6}$ anion group $(1.994 \AA)$ to a rather weak bent Type $2[10] \mathrm{C}-\mathrm{H} \cdots \mathrm{F}$ contact between H7A and the F4 (2.643 $\AA)$ as shown in Figure 3. The dominating stronger Type 1 halogen-hydrogen interactions lead to the formation of 1D chain along $b$-axis as shown in Figure 4. 


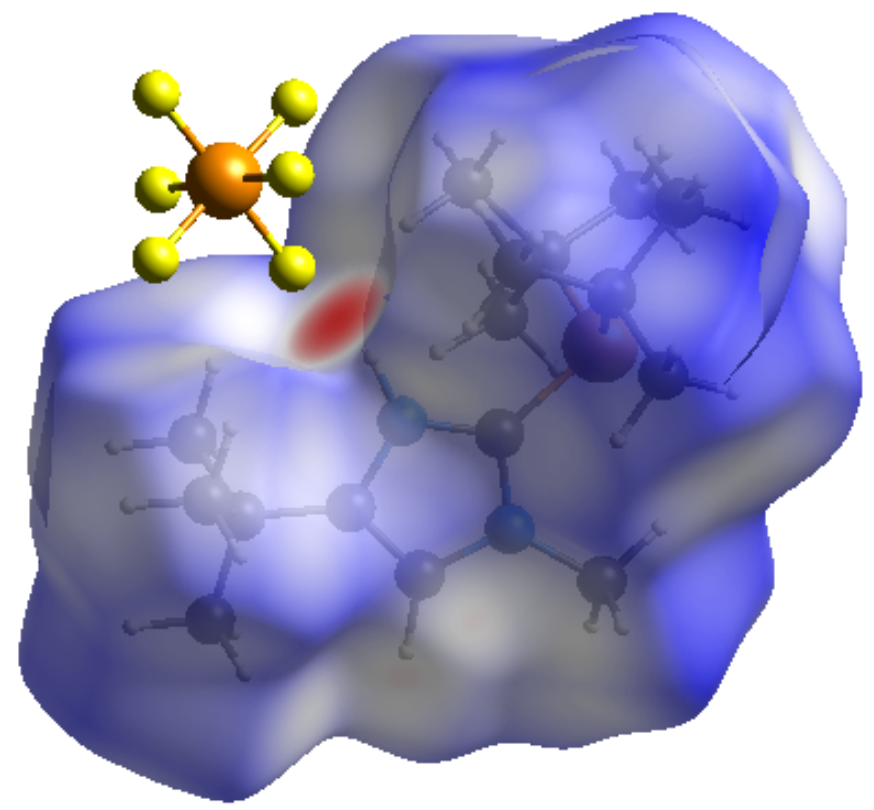

Figure 2. Hirshfeld surface analysis of complex 1 (red contours indicating close contacts).

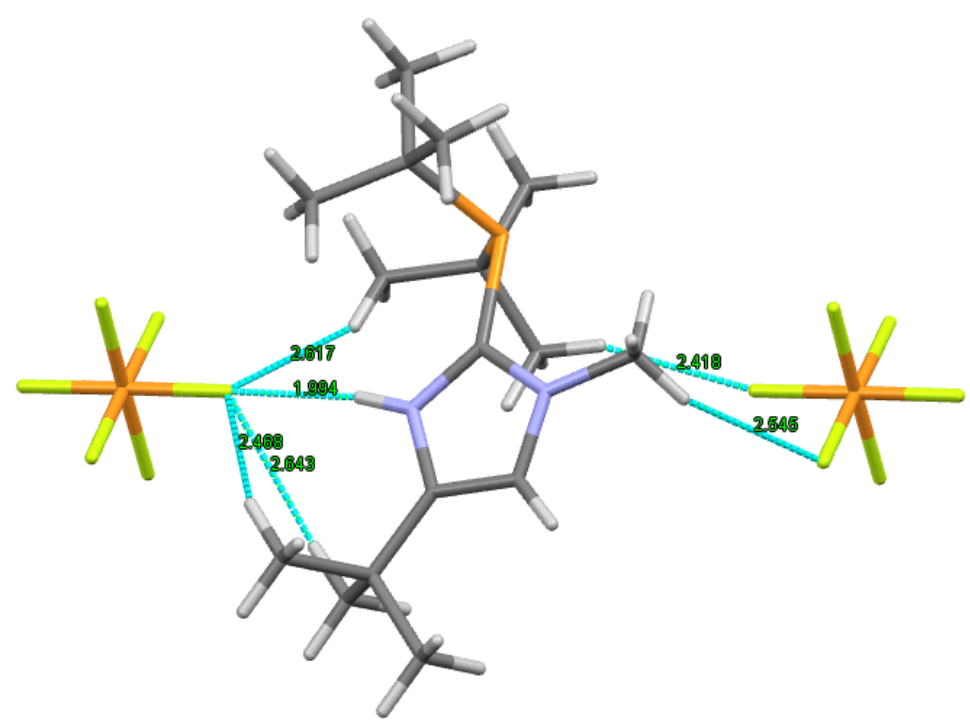

Figure 3. An array of weak and strong halogen-hydrogen interactions involving the $\mathrm{PF}_{6}$ anion in complex 1.

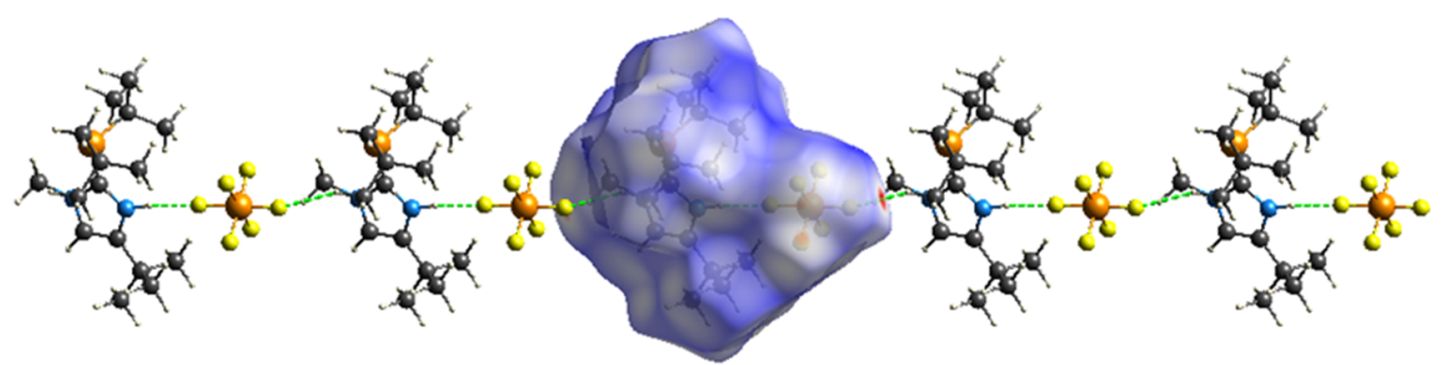

Figure 4. Halogen-hydrogen interaction (seen along the c-axis) leading to 1-D chain along $b$-axis.

\section{Materials and Methods}

All experiments were performed under dry nitrogen atmosphere using standard Schlenk techniques. Diethyl ether was distilled from sodium/benzophenone and stored over 4 Å molecular 
sieves. Acetone was dried using $\mathrm{B}_{2} \mathrm{O}_{3}$ as a drying agent. Anhydrous DCM was transferred to and stored over 4 Å molecular sieves. Dried solvents were degassed by means of reduced pressure. ${ }^{t} \mathrm{Bu}_{2} \mathrm{PIm}$ was prepared according to method described in literature [4]. NMR spectra were recorded at $25^{\circ} \mathrm{C}$ on JEOL ECA 400 spectrometer $\left(400 \mathrm{MHz}\right.$ listed below for ${ }^{1} \mathrm{H}=399.763 \mathrm{MHz}, 100 \mathrm{MHz}$ for ${ }^{13} \mathrm{C}\left\{{ }^{1} \mathrm{H}\right\}=$ 100.525 MHz and $161 \mathrm{MHz}$ for $\left.{ }^{31} \mathrm{P}=161.922 \mathrm{MHz}\right) .{ }^{1} \mathrm{H}$ NMR chemical shifts are reported in parts per million to low field relative to tetramethylsilane and referenced to residual solvent resonances. ${ }^{31} \mathrm{P}\left\{{ }^{1} \mathrm{H}\right\}$ NMR chemical shifts were referenced to an external $85 \%$ aqueous $\mathrm{H}_{3} \mathrm{PO}_{4}$ capillary placed in the solvent. NMR signals are listed in low to high field order followed by peak multiplicity, coupling constants $\mathrm{J}$ in Hertz and peak integration in parentheses.

\section{Synthesis of Phosphine-Imidazolium Salt [ ${ }^{t} \mathrm{Bu}_{2} \mathrm{PImH} \mathrm{PF}_{6}$}

A stock solution of ${ }^{t} \mathrm{Bu}_{2} \mathrm{PIm}(2 \mathrm{~mL}, 0.22 \mathrm{M}$ in acetone, $0.44 \mathrm{mmol})$ was transferred into a $50-\mathrm{mL}$ Schlenk flask and all volatiles were removed in vacuo. The phosphine was redissolved in $5 \mathrm{~mL}$ of diethyl ether and $\mathrm{HCl}$ solution $(0.11 \mathrm{~mL}, 4 \mathrm{M}$ in dioxane, $0.44 \mathrm{mmol})$ was added. The mixture was allowed to stir for $1 \mathrm{~h}$ after which the white precipitate was isolated by filtration, washed with ether and dried under reduced pressure. Five milliliters DCM was added to the flask followed by the suspension of $\mathrm{KPF}_{6}$ in $5 \mathrm{~mL} \mathrm{DCM}$. The mixture was left stirring overnight, after which DCM was removed in vacuo. Extraction with acetone (two 3-mL portions) and removal of all volatiles under reduced pressure afforded the compound [ ${ }^{t} \mathrm{Bu}_{2} \mathrm{PImH}_{\mathrm{P}} \mathrm{PF}_{6}$ as fine white powder, $168 \mathrm{mg}(89 \%) .{ }^{1} \mathrm{H} \mathrm{NMR}(400 \mathrm{MHz}$, acetone- $\left.d_{6}\right) \delta 12.02(\mathrm{br} \mathrm{s}, 1 \mathrm{H}), 7.75(\mathrm{~s}, 1 \mathrm{H}), 4.20(\mathrm{~s}, 3 \mathrm{H}), 1.46(\mathrm{~s}, 9 \mathrm{H}), 1.34(\mathrm{~s}, 9 \mathrm{H}), 1.31(\mathrm{~s}, 9 \mathrm{H}) \mathrm{ppm} .{ }^{13} \mathrm{C}\left\{{ }^{1} \mathrm{H}\right\}$ NMR $\left(100 \mathrm{MHz}\right.$, acetone- $\left.d_{6}\right) \delta 145.9(\mathrm{~d}, J=2.3), 145.4(\mathrm{~d}, J=63.5), 145.1(\mathrm{~s}), 37.02(\mathrm{~d}, J=20.1), 33.5$ $(\mathrm{d}, J=20.1), 31.0(\mathrm{~s}), 29.4(\mathrm{~s}), 28.2(\mathrm{~s}) \mathrm{ppm} .{ }^{31} \mathrm{P}\left\{{ }^{1} \mathrm{H}\right\} \mathrm{NMR}\left(161 \mathrm{MHz}\right.$, acetone- $\left.d_{6}\right) \delta 10.9(\mathrm{~s}),-143.6$ (sept, ${ }^{1} J_{\mathrm{PF}}=709 \mathrm{~Hz}$ ) ppm. Elemental Anal. (Perkin Elmer PE 2400 II CHONS): calcd for C16H32F6N2P2: C, 44.86; H, 7.53; N, 6.54; Found: C, 44.98; H, 7.53; N, 6.55.

Supplementary Materials: CCDC 2003050 contains the supplementary crystallographic data for compound 1. These data can be obtained free of charge via http://www.ccdc.cam.ac.uk/conts/retrieving.html or from the Cambridge Crystallographic Data Center, 12 Union Road, Cambridge CB2 1EZ, UK; fax: +44 1223-336-033; or email: deposi@@ ccdc.cam.ac.uk.

Author Contributions: A.V.S. prepared the compound; V.J. designed the experiments, R.G. collected and analyzed the X-ray data and wrote the study. All authors have read and agreed to the published version of the manuscript.

Funding: This research received no external funding.

Acknowledgments: The authors acknowledge the help for Drasko V, Monash University for some of the discussions.

Conflicts of Interest: The authors declare no conflict of interest.

\section{References}

1. Grotjahn, D.B.; Incarvito, C.D.; Rheingold, A.L. Combined effects of metal and ligand capable of accepting a proton or hydrogen bond catalyze anti-Markovnikov hydration of terminal alkynes. Angew. Chem. Int. Ed. 2001, 40, 3884-3887. [CrossRef]

2. Grotjahn, D.B.; Larsen, C.R.; Gustafson, J.L.; Nair, R.; Sharma, A. Extensive isomerization of alkenes using a bifunctional catalyst: An alkene zipper. J. Am. Chem. Soc. 2007, 129, 9592-9593. [CrossRef] [PubMed]

3. Erdogan, G.; Grotjahn, D.B. Mild and selective deuteration and isomerization of alkenes by a bifunctional catalyst and deuterium oxide. J. Am. Chem. Soc. 2009, 131, 10354-10355. [CrossRef] [PubMed]

4. Grotjahn, D.B.; Gong, Y.; Zakharov, L.; Golen, J.A.; Rheingold, A.L. Changes in coordination of sterically demanding hybrid imidazolylphosphine ligands on $\mathrm{Pd}(0)$ and $\mathrm{Pd}(\mathrm{II})$. J. Am. Chem. Soc. 2006, 128, 438-453. [PubMed]

5. Smarun, A.V.; Shahreel, W.; Pramono, S.; Koo, S.Y.; Tan, L.Y.; Ganguly, R.; Vidović, D. Influence of increasing steric demand on isomerization of terminal alkenes catalysed by bifunctional ruthenium complexes. J. Organomet. Chem. 2017, 834,1-9. [CrossRef] 
6. Smarun, A.V.; Petković, M.; Shchepinov, M.S.; Vidović, D. Site-specific deuteration of polyunsaturated alkenes. J. Org. Chem. 2017, 82, 13115-13120. [CrossRef] [PubMed]

7. Ge, Y.; Cui, X.-Y.; Tan, S.M.; Jiang, H.; Ren, J.; Lee, N.; Lee, R.; Tan, C.-H. Guanidine-Copper Complex Catalyzed Allylic Borylation for the Enantioconvergent Synthesis of Tertiary Cyclic Allylboronates. Angew. Chem. Int. Ed. Engl. 2019, 58, 2382-2383. [CrossRef] [PubMed]

8. Turner, M.J.; McKinnon, J.J.; Wolff, S.K.; Grimwood, D.J.; Spackman, P.R.; Jayatilaka, D.; Spackman, M.A. CrystalExplorer17; University of Western Australia: Perth, Australia, 2017.

9. Mukherjee, A.; Tothadi, S.; Desiraju, G.R. Halogen Bonds in Crystal Engineering: Like Hydrogen Bonds yet Different. Acc. Chem. Res. 2014, 47, 2514-2524. [CrossRef] [PubMed]

10. Cavallo, G.; Metrangolo, P.; Milani, R.; Pilati, T.; Priimagi, A.; Resnati, G.; Terraneo, G. The Halogen Bond. Chem. Rev. 2016, 116, 2478-2601. [CrossRef] [PubMed]

(C) 2020 by the authors. Licensee MDPI, Basel, Switzerland. This article is an open access article distributed under the terms and conditions of the Creative Commons Attribution (CC BY) license (http://creativecommons.org/licenses/by/4.0/). 